\title{
A Minimally Invasive Approach to the Lumbar Neural Foramen and Extraforaminal Compartment: Modified Surgical Technique
}

\section{Michael S. Virk* and Eric Elowitz}

Department of Neurological Surgery, Weill Cornell Medical College, New York Presbyterian Hospital, New York, New York, USA

\begin{abstract}
Surgical approaches to the neural foramen and the lateral extraforaminal space in the lumbar spine are required to treat far lateral disc herniations and shwannomas. The MetRx tubular retractor system facilitates a minimally invasive technique that directly targets the region delineated by Kambin's triangle. This study presents technical modifications, described in a step-wise fashion, to previously published approaches.
\end{abstract}

We reviewed the charts of 47 patients that underwent surgery for pathology located in Kambin's Triangle using the modified technique described here. Important technical adjustments include docking on the pars interarticularis, minimal shaving of the lateral pars and inferior articulating process, and palpation of the pedicle as a reference point for opening the ligamentumflavum and locating the exiting nerve. Potential pitfalls and strategies to avoid them are also noted.

All 47 patients reported a successful outcome with the procedure, there were no complications or revisions, and all were discharged home within 24 hours of the procedure. Key elements of the procedure were highlighted with supporting illustrations and intra-operative imaging.

The minimally-invasive approach performed through MetRx tubular retractors is a safe and successful surgical method for treating pathology localized in the neural foramen and lateral extraforaminal space between L1- L5 vertebrae.

Keywords: MIS; Far-lateral; Extraforaminal; Tubular retractor; Kambin's triangle

\section{Introduction}

Lumbar spine pathology located within the neural foramen and extending laterally into the extraforaminal space can be challenging to access. Surgical indications requiring an approach to the lateral interpedicular compartment include mechanical nerve root compression caused by "far lateral" lumbar disc herniations and other degenerative disease resulting in foraminal stenosis. Additionally, schwannomas can occur in this location. This region of interest was first described by Parviz Kambin in a series of publications [1] and is delineated on lateral radiographs by the exiting nerve root (hypotenuse), the superior end plate of the caudal vertebral body (base) and the common dural tube or traversing nerve root (height). Options for reaching Kambin's triangle include open procedures and minimally invasive approaches employing an endoscope or a tubular retractor system or a combination of both.

Traditional open approaches to this region are achieved via a midline or paramedian incision [2,3]. Midline incisions range from $4-8 \mathrm{~cm}$ and must be long enough to accommodate a wide sub-periosteal dissection so that muscle may be retracted laterally beyond the pars interarticularis and facet joints, which may require removal for adequate visualization. The paramedian approach travels along an oblique trajectory directly to the neural foramen, but requires considerable muscle dissection. This approach is hindered by cumbersome conventional retractors and is void of clear landmarks that facilitate optimal targeting, though is generally preferred over the midline approach.

The percutaneous endoscopic approach utilizing a guide wire introduced via a lateral stab incision for accessing extraforaminal pathology is advocated by some authors [4-7]. The spectrum of pathology that can be adequately treated is limited however by visualization, instrument availability, and achieving adequate hemostasis. Recently published series document nerve root injury, conversion to open procedures and returning to the operating room at a later date to address recurrence[4,6-8]. These complications likely reflect the steep learning curve and need for careful case selection.
Minimally invasive approaches incorporating a tubular retractor system and an operating microscope are ideally suited to access Kambin's triangle [9-12]. An $18 \mathrm{~mm}$, low profile retractor, can be introduced through a $2 \mathrm{~cm}$ skin incision and establishes a direct corridor to the region of interest via muscle dilation. It can be guided directly to its docking point via fluoroscopy and known bony landmarks, thus offsetting risk. Nominal bone excision minimizes potential joint destabilization and denervation. These technical benefits potentially translate to decreased tissue trauma and blood loss, decreased post-operative analgesic usage, decreased surgical site infections, earlier mobilization, reduced length of hospital stay, earlier return to work, and decreased operative cost [13-18]. Here we propose modifications to the tubular retractor approach to Kambin's Triangle initially described by Richard Fessler's group [12], and present a 47 patient series. The goal of these modifications is to provide clear anatomical landmarks in a region that is not commonly approached in order to facilitate consistent reproducibility, safety, and successful patient outcomes.

\section{Methods}

\section{Patients}

Between November 2002 and July 2012, 47 patients underwent

*Corresponding author: Michael S. Virk, Department of Neurological Surgery, Weill Cornell Medical College, New York Presbyterian Hospital, 525 E. 68th St., Box 99 (Baker F-2218), New York, NY, 10065, USA, Tel: (212) 746-9819; E-mail: miv2010@ nyp.org

Received November 10, 2013; Accepted December 10, 2014; Published December 12, 2014

Citation: Virk MS, Elowitz E (2014) A Minimally Invasive Approach to the Lumbar Neural Foramen and Extraforaminal Compartment: Modified Surgical Technique. J Spine 4: 203. doi:10.4172/2165-7939.1000203

Copyright: (c) 2014 Virk MS, et al. This is an open-access article distributed under the terms of the Creative Commons Attribution License, which permits unrestricted use, distribution, and reproduction in any medium, provided the original author and source are credited. 
surgery for lumbar spine pathology located in Kambin's Triangle via a minimally invasive tubular retractor system. All cases addressed degenerative changes or herniated intervertebral discs except one case that involved a foraminalschwannoma (Figure 1). Patient charts were reviewed retrospectively and characteristics are summarized in Table 1. All patients were evaluated in the clinic by history and physical exam, as well as MRI. Conservative treatment was initially attempted, including non-steroidal anti-inflammatory medications, steroid injections, and physical therapy. Patients were selected for surgery if pain, sensory (numbness or parasthesias) or motor (weakness) symptoms persisted despite these measures. In this series, the vast majority of patients presented with radicular pain corresponding to the compressed nerve root. All patients were discharged following recovery in the postanesthesia recovery room within $24 \mathrm{hrs}$ of their procedure. Followup appointments were scheduled routinely at two and six weeks postoperatively. Patients were assessed by interval history and follow up neurological exam. Post-op imaging was not obtained.

\section{Surgical technique}

The MetRx tubular retraction system (Medtronic, Minneapolis, MN, USA) was used to approach foraminal and extraforaminal pathology in a unilateral, minimally invasive fashion. Patients were anesthetized, intubated, and turned into the prone position on a Cloward Surgical Saddle (Cloward Instruments, Honolulu, HI, USA). One dose of antibiotics was administered pre-operatively. Midline was marked and the correct spinal level identified under fluoroscopy. All exposed skin was covered with ioban, though this was removed in the region immediately surrounding the incision so that no ioban was introduced through the incision by retractor placement.

A $2 \mathrm{~cm}$ incision was made $2 \mathrm{~cm}$ lateral to midline, ipsilateral to the pathology, and the thoracolumbar fascia was opened with a stab incision $(1 \mathrm{~cm})$ by scalpel or bovieelectrocautery. The initial dilator was introduced through the fascial incision and docked on the lateral aspect of the pars interarticularis under fluoroscopic guidance (Figures 2a,3a and $3 \mathrm{~b}$ ). This was identified as a flat surface with sharply demarcated step-off as the dilator was moved laterally. Neither K-wires nor Steinmann pins were used as these risk potential durotomy or nerve root injury. Serial dilation took place until the $18 \mathrm{~mm}$ tubular retractor was inserted over the final dilator and fixed to the table with the articulated, locking arm. Final placement was confirmed with fluoroscopy (Figure $2 b$ ). Only the initial dilator and retractor placement were confirmed with X-ray (Figure 2a and 2b); no fluoroscopy was used beyond this point. Dilators were twisted as they were advanced in order to displace as much muscle tissue as possible. An illustrative schematic of the relationship between the tubular retractor and the relevant anatomy is presented in Figures 3 and 4.

The procedure was then conducted through the operative microscope (Figures 4 and 5a-5f). Any soft tissue not displaced by the retractors was removed with cautery to expose underlying bony landmarks. These were defined medially by the lateral aspect of the pars and caudally by the inferior facet (Figure $4 \mathrm{a}$ and $5 \mathrm{a}$ ). To enhance medial exposure, the edge of the lateral pars was removed by drill and Kerrisonrongeur as necessary. Caudal exposure was obtained by partially drilling the superior-lateral aspect of the superior articular process (Figures $4 \mathrm{~b}, 4 \mathrm{c}$ and $5 \mathrm{~b}$ ). The ligamentumflavum was visualized deep to the pars and extending laterally to it. Because the ligament does not insert on the pedicle at the cranial aspect of the foramen, it was opened and resected with a Kerrisonrongeur or Penfield retractor at that point. A ball-tip probe was used to palpate the pedicle to confirm localization. The ligamentous opening was expanded until Kambin's triangle and all relevant pathology was exposed.
There are several points to emphasize with respect to the steps described above. Facet joint hypertrophy, when present, can be an obstacle to retractor placement, particularly in lordotic lumbar spines. For most cases, the inferior facet, or simply the superior articular process, required partial drilling. The superior facet and transverse process did not require exposure or removal, as these were rostral to the region of interest. When dissecting laterally, care was taken to identify the segmental artery that was often in close association with the exiting nerve (Figure $5 \mathrm{c}$ ). This was sacrificed with bipolar electrocautery if deemed necessary. Also, in order to expose and remove extruded disc, the nerve root was often gently retracted superior-laterally (Figure $5 \mathrm{~d}$ and 5e). Retraction was kept to a minimum in order to avoid excessive manipulation of the dorsal root ganglion (DRG) that is located at the foramen.

Once the working channel was established, the pathology - disc, bone, ligament, soft tissue, tumor - was addressed (Figures $4 \mathrm{c}$ and $5 \mathrm{~d}-$ 5f). Disc extrusions often followed the exiting nerve root in its course so an examination inferior and anterior to the nerve is important. At the conclusion of the procedure the wound was irrigated copiously with antibiotics. The retractor was slowly withdrawn and bipolar cautery was used to control and excess muscle bleeding. A single suture was used to close the fascia before approximating the skin and closing with deep dermal and subcuticular sutures. Patients were discharged home after recovering from anesthesia on the same day as the procedure or the following morning. No post-operative antibiotics were prescribed, however, all patients were sent home with oral analgesics to be taken as needed.

\section{Results}

Patient age ranged from 39-87, 29 (62\%) were men, and for 46 patients microdiscetomy with or without foraminotomy was the primary indication; while one patient had a schwannoma resection

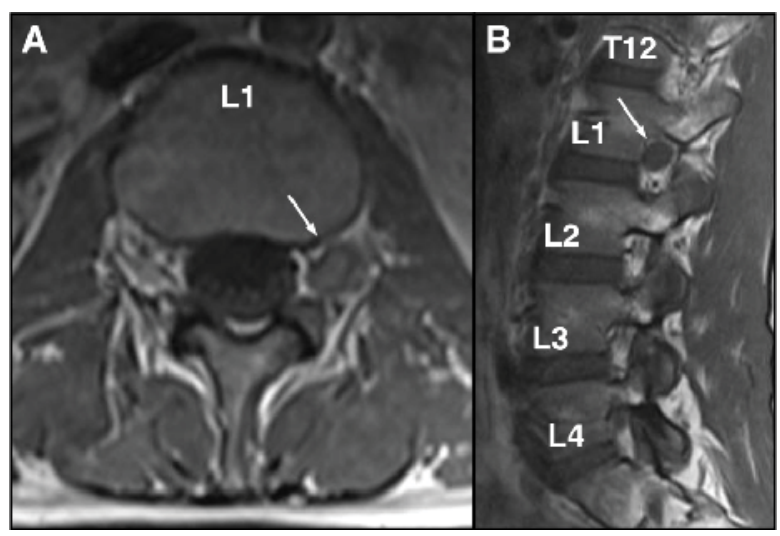

Figure 1: Magnetic resonance image of left $L 1 / L 2$ foraminal schwannoma (arrow). a) Axial cut, T1 image post-gadolinium contrast; b) Sagittal cut, T1 image.

\begin{tabular}{|c|c|c|c|c|c|c|}
\hline $\begin{array}{c}\text { Patients } \\
\text { (n) }\end{array}$ & Level & $\begin{array}{c}\text { Side } \\
\text { (R:L) }\end{array}$ & $\begin{array}{c}\text { Age (range, } \\
\text { years) }\end{array}$ & $\begin{array}{c}\text { Gender } \\
\text { (M:F) }\end{array}$ & Schwannoma & Complications \\
\hline 6 & L2/3 & $1: 5$ & $43-76$ & $4: 2$ & 1 & 0 \\
\hline 17 & L3/4 & $6: 11$ & $39-87$ & $10: 7$ & 0 & 0 \\
\hline 24 & L4/5 & $12: 12$ & $39-78$ & $15: 9$ & 0 & 0 \\
\hline $\begin{array}{c}\text { Sum/ } \\
\text { Avg }^{*} 47\end{array}$ & & $19: 28$ & $58 \pm 11$ & $29: 18$ & 1 & 0 \\
\hline
\end{tabular}

*Total values are listed for all columns except Age where mean \pm standard deviation is presented.

Table 1: Patient Deographics. 


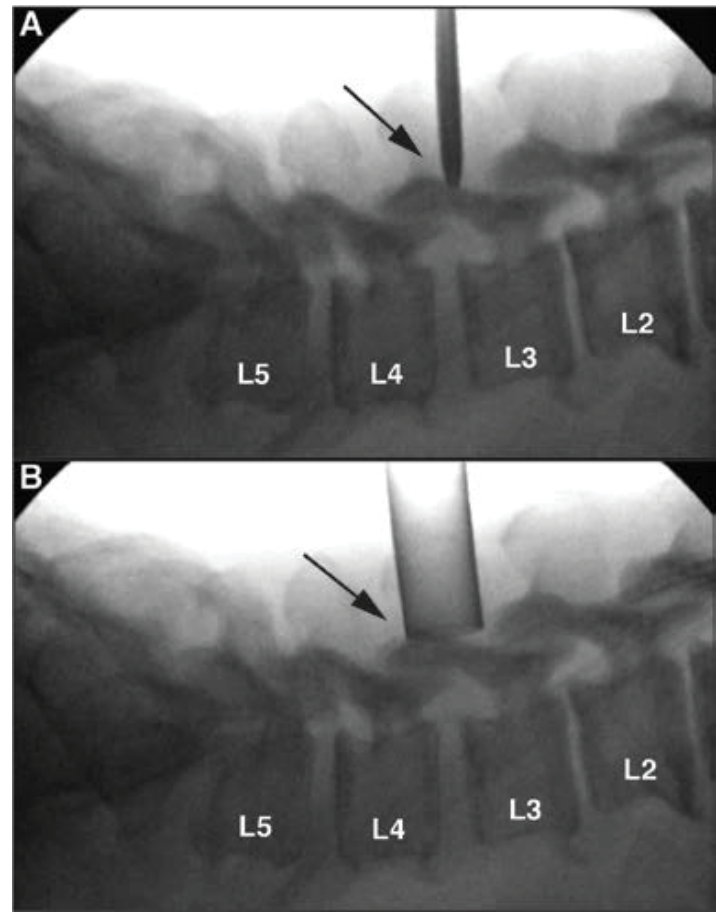

Figure 2: Intraoperative lateral view x-ray of lumbosacral spine. a) The initial dilator (arrow) is docked on lateral aspect of the pars interarticularis, directly above the L3-L4 neuroforamen. b) The $18 \mathrm{~mm}$ tubular dilator is docked such that the pars interarticularis forms the medial border and the inferior articular process forms the caudal border.

(Table 1). There were $5(11 \%)$ far-lateral disc herniations at L2/3, 17 (37\%) at L3/4 and $24(52 \%)$ at L4/5. Of the 46 disc far-lateral disc herniations 19 (41\%) occurred on the right, while 27 (59\%) occurred on the left. There were no post-operative hematomas, dural tears, returns to the operating room, or wound infections. Operative time did not exceed 60 minutes and intraoperative blood loss was recorded as less than $10 \mathrm{cc}$ for each case. Patients were evaluated at 2-week and 6-week follow up appointments. All patients reported improvement in their presenting symptoms by the 6-week follow up appointment and no post-op imaging was obtained in any patient because there was no indication. To date, no patients have returned to clinic after their 6-week scheduled follow up appointment with either recurrent or new symptoms, including pain, at the level or side of the initial operation, and none required re-operation at the original level.

\section{Discussion}

The far lateral approach utilizing MetRx tubular retractors is a safe, minimally invasive procedure that provides access to the compartment described by Kambin's triangle - within the neural foramen and lateral to it. The most prevalent pathology located in this region of the lumbar spine is degenerative, consisting primarily of extruded intervertebral discs and ligamentous hypertrophy. Far lateral disc herniations represent $7-15 \%$ of all lumbosacral disc herniations $[14,19,20]$, however, dorsal root ganglion involvement is common and results in painful radiculopathy. Schwannomas can also be encountered in this location and are amenable to excision with the technique described here [21,22]. This approach is thus being presented as an approach to a region rather than for a specific indication. The goal remains to decompress the foraminal and extraforaminal nerve root while incurring minimal tissue trauma and exposure to risk. In this retrospective case review, no patients were taken back to the operating room after recovering from anesthesia, there were no complications (neurological deficits, dural tears, hematomas or infections), nor did any patients undergo re-operation for the initial indication. We advocate the technique described here as a highly effective and successful method for accessing lumbar pathology in Kambin's triangle.

\section{Surgical technique}

The purpose of modifying the previously described approach to Kambin's triangle through tubular retractors [12] is to provide clear anatomical features that facilitate consistent localization, docking, and nerve root exposure. Because pathology in this region is not as common as that within the canal, surgeons generally have less experience with extraforaminal approach. The specific landmarks and step-wise technique proposed here are meant to aid reproducibility and optimize surgical outcomes.

Previous publications suggest docking at the junction of the transverse process and superior facet joint, exposing these structures, and then redirecting the retractor caudally before initiating the dissection to the nerve root $[10,12]$. These studies also recommend using either Steinmann pins or K-wires prior to the initial dilator, which can be a potential source of unintentional durotomy, nerve root injury or vascular penetration. However, we propose targeting the pars with the initial dilator for three reasons: it can be clearly detected by palpation, it is directly centered above the region of interest, and it eliminates the unnecessary removal of soft tissue from the superior facet joint and transverse process. There is no need to redirect the retractor after initial docking. Second, after excising the lateral most edge of the pars, the ligamentumflavum can be opened at the cranial aspect of the foramen where it traverses the inferior aspect of the pedicle without inserting on it. Third, upon opening the ligament, a ball-tip probe can be used to palpate the pedicle, which further serves as a point of localization. These three maneuvers serve to confirm the correct trajectory to the nerve root.

Several additional technical considerations optimize this approach and differ from previously described techniques. While initial dilator placement often proceeds without obstruction, hypertrophied facet joints, further compounded by lordotic spines, can impede placement of the final dilator. The patient should be positioned on a surgical table that minimizes lordosis; we routinely employ use of the

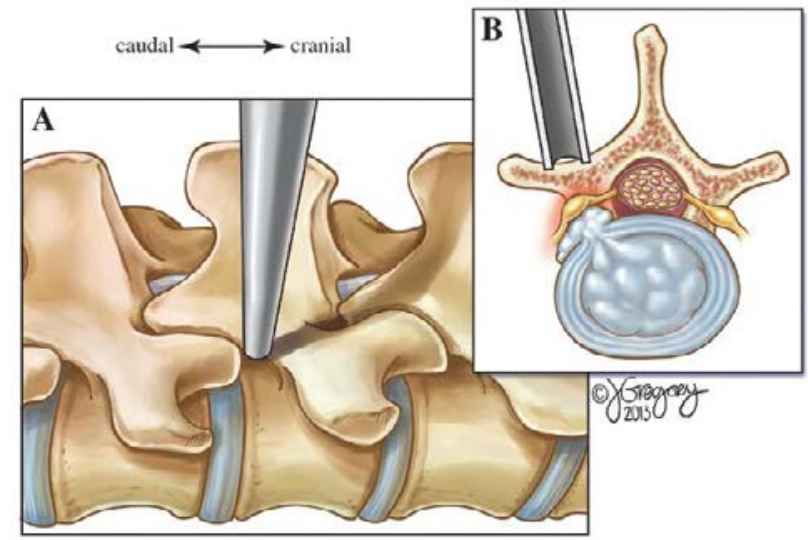

Figure 3: Lumbar spine anatomy with placement of initial dilator and $18 \mathrm{~mm}$ MetRx tubular retractor. A) Right side, sagital view of lumbar spine. Initia dilator is docked on lateral aspect of pars interarticularis. B) Axial view of initial dilator position. Exiting nerve root, dorsal root ganglion, and extraforaminal disc extrusion are shown. Cranial/caudal orientation is depicted by arrows. 


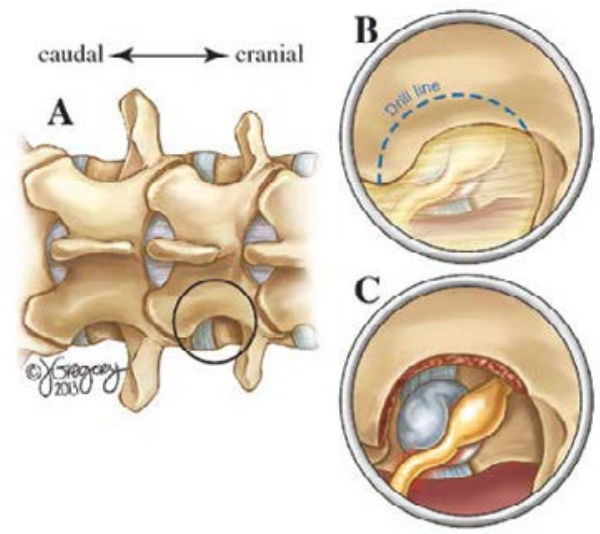

Figure 4: Lumbar spine anatomy and approach to Kambin's triangle through $18 \mathrm{~mm}$ MetRx tubular retractor. A) Coronal view of lumbar spine with footprint of $18 \mathrm{~mm}$ tubular retractor outlined by black circle. B) Operating microscope view through tubular retractor with ligamentum flavum intact. Dashed blue line indicates region of lateral pars and inferior articulating process that may require drilling to access pathology. C) After drilling and opening ligamentum flavum, exiting nerve root and disc are visualized in extraforaminal compartment. Cranial/caudal orientation is depicted by arrows.

Cloward Surgical Saddle (Cloward Instruments, Honolulu, HI, USA). Fluoroscopy should be used after placing the initial dilator and the final retractor to confirm satisfactory position (Figure 2). Obtaining images at just these two points limits patient and staff exposure to radiation. If the final retractor does not seat well, the superior-lateral aspect of the inferior facet may require partial drilling through the tube to increase caudal exposure and optimize retractor placement (Figures 3-5). As mentioned above, it is not necessary to expose the superior facet or the transverse process. These are rostral to the region of interest when the dilators are placed properly. Unnecessary exposure of either can cause additional post-operative pain for the patient and dissecting the facet joint risks damage or denervation, which can ultimately lead to instability.

The final two points involve caution around the segmental and/or radicular artery and the DRG. When performing an extraforaminal dissection, the arterial supply is often visible in close proximity to the pars interarticularis and should be preemptively cauterized if it is at risk of avulsion during the procedure $[1,12,23]$. Bleeding in this location can be difficult to control and has been reported to cause postop hematomas with the percutaneous endoscopic approach [24-29]. The nerve root generally requires retraction to successfully visualize the disc fragment or access the anterior foramen, however, the DRG should be manipulated cautiously. While intra-operative steroids can be used, care taken to minimize retraction may prevent the associated post-operative dysathesias resulting from DRG compression.

This technique is applicable without modification to both obese and elderly populations. For obese patients, a longer tubular retractor may be required although the incision and final tube diameter remain constant at $2 \mathrm{~cm}$ and $18 \mathrm{~mm}$, respectively. With open procedures, however, deeper targets, as is the case in obese patients, necessitate longer incisions and more soft tissue dissection. Open approaches for intracanalicular lumbar disc herniations in the obese are often associated with higher complication rates, though this has not been reported for tubular approaches [30,31]. In the elderly population, smaller incisions and minimal dissection of soft tissue and bone along with decreased post-operative analgesic requirements, may translate to faster mobilization. In this series, patients over 65 years old did not require greater recovery time.
The three primary approaches to Kambin's triangle include a traditional open approach via midline or paramedianincisions, and two minimally invasive approaches employing tubular retractors or percutaneously introduced endoscopes. Open procedures require long incisions, extensive muscle cautery, wide subperiosteal dissections, and potential pars and/or facet excision [2,5,32,33]. Secondary consequences may include excessive intra-operative blood loss, postoperative pain and muscle wasting due to interrupted blood supply and denervation [34-36] as well as possible instability requiring subsequent surgical stabilization $[5,32,37,38]$ and higher wound surgical site infection rate $[16,18]$. Both minimally invasive techniques seek to eliminate these features of open surgery by taking advantage of small incisions and establishing narrow surgical corridors that directly target foraminal and extraforaminal pathology.

Several studies demonstrate the efficacy of percutaneous endoscopic approaches to the neural foramen. Specifically, these procedures use a combination of needles, guide wires and discography to guide an endoscope and localize the pathology. This is in contrast to techniques that simply introduce a microscope and/or endoscope through a tubular retractor. Percutaneous endoscopic procedures are not without challenges and associated complications. Visualization is limited to the tip of the endoscope and angled scopes must be available (20-90 degree); the working space is extremely small and must be created by removing tissue while maintaining the cavity by continuous injected saline; migrated fragments may be difficult to locate and only those in line with the trajectory of the scope are visualized $[4,27,39]$.

Other groups using tubular retractor systems to address far lateral disc herniations have published excellent results with minimal complications. Voyadzis et al. presented the original technique description along with a series of 20 patients using the MetRx retractor system and report improvement in all but 2 patients. These two had temporary neuropathic pain that resolved within months. Importantly, there were no complications, average hospital stay was 8 hours and $80 \%$ of the patients were discharged the same day, which is consistent with our results. Salame and Lidar used the MetRx system on 31 patients and reported 1 recurrence requiring operative intervention and 2

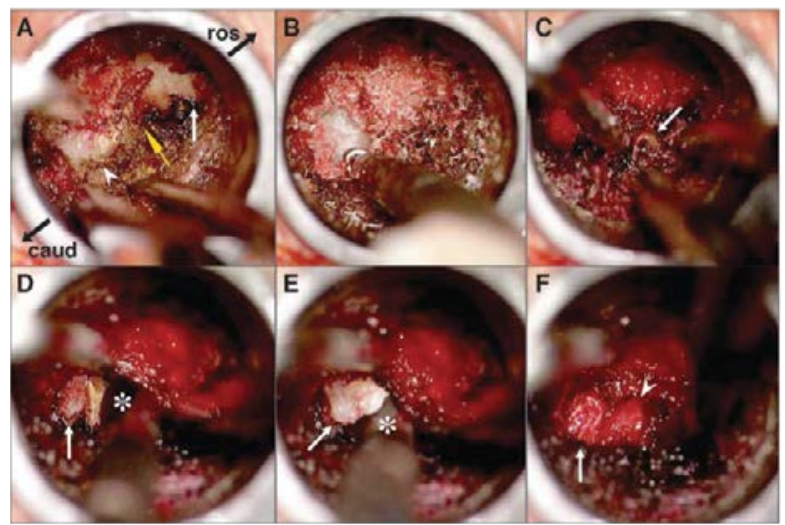

Figure 5: Intra-operative view of surgical field for right L4/L5 far-latera discetomy through $18 \mathrm{~mm}$ MetRx tubular retractor. A) Requisite bony exposure demonstrates the pars interarticularis (yellow arrow) at junction with transverse process (white arrow, not exposed) and superior-lateral aspect of IAP (arrow head). Rostral-Caudal orientation indicated by black arrows. B) Shaving superior-lateral IAP and lateral pars. C) Segmental artery (arrow) before cautery. D) Disc bulge (arrow) exposed, L4 nerve retracted by penfield retractor (asterisk). E) Herniated nucleus pulposa (arrow) expressed with penfield retractor (asterisk). F) Decompressed L4 nerve (arrow head) and void left by discetomy (arrow). ros - rostral, caud - caudal, IAP - inferior articulating process. 
dural tears that were addressed by water-tight facial closure, but no symptoms of CSF leakage, and no other complications.

It is important to note that no L5-S1 extraforaminal pathology was addressed in the current study. This level is particularly challenging from an anatomical standpoint because of the iliac crest and sacral ala, as well as large, closely approximated transverse processes and zygahypophyseal joints. Voyadzis et al. included 1 case in a series of 20 at this level and the case required a modified approach. Salame and Lidar describe drilling the lateral third of the facet joint in order to gain the required exposure and report success in all 6 patient undergoing surgery at L5-S1.

\section{Conclusion}

Our results for 47 patients undergoing surgery for far-lateral pathology delineated by Kambin's triangle at levels L1-5 with tubular retractors demonstrate that this is a safe and effective technique. Specifically, there were no operative complications such as dural tears, hematomas or infections; all patients went home within 24 hours there were no recurrences and no patients required re-operation at the index level. All patients reported improvement with respect to pain and motor function at the follow up appointment within 6 weeks. The sequential description and precise anatomical landmarks proposed offer modifications to initial descriptions in order to facilitate reproducibility and consistent outcomes. Included among these are the following: docking the initial retractor on the pars interarticularis; opening the ligamentumflavum where it traverses the pedicle superiorly within the foramen; and palpating the pedicle with a ball tip probe to aid in localization of the exiting nerve root. This technique can be applied to all patient populations, including the obese and elderly in a safe and effective manner.

\section{Disclosure}

Neither Michael Virk nor Eric Elowitz has any conflicts of interest. Both authors completed this work with strict adherence to ethical standards. A Weill Cornell Medical College - New York Presbyterian Hospital IRB was obtained for retrospective patient chart review required to perform this study.

Michael Virk has no financial disclosures.

Eric Elowitz has one financial disclosure: he is a consultant for Nuvasive, Inc.

\section{References}

1. Kambin P, Brager MD (1987) Percutaneous posterolateral discectomy Anatomy and mechanism. Clin Orthop Relat Res: 145-154.

2. Chang SB, Lee SH, Ahn Y, Kim JM (2006) Risk factor for unsatisfactory outcome after lumbar foraminal and far lateral microdecompression. Spine (Phila Pa 1976) 31: 1163-1167.

3. Marquardt G, Bruder M, Theuss S, Setzer M, Seifert V (2012) Ultra-long-term outcome of surgically treated far-lateral, extraforaminal lumbar disc herniations: a single-center series. Eur Spine J 21: 660-665.

4. Choi G, Lee S-H, Bhanot A, Raiturker PP, Chae YS, et al. (2007) Percutaneous endoscopic discectomy for extraforaminal lumbar disc herniations: extraforaminal targeted fragmentectomy technique using working channel endoscope. Spine 32: E93-99.

5. Epstein NE (1995) Different surgical approaches to far lateral lumbar disc herniations. J Spinal Disord 8: 383-394.

6. Lübbers T, Abuamona R, Elsharkawy AE (2012) Percutaneous endoscopic treatment of foraminal and extraforaminal disc herniation at the L5-S1 level. Acta Neurochir (Wien) 154: 1789-1795.

7. Sasani M, Ozer AF, Oktenoglu T, Canbulat N, Sarioglu AC (2007) Percutaneous endoscopic discectomy for far lateral lumbar disc herniations: prospective study and outcome of 66 patients. Minim Invasive Neurosurg 50: 91-97.
8. Choi I, Ahn JO, So WS, Lee SJ, Choi IJ, et al. (2013) Exiting root injury in transforaminal endoscopic discectomy: preoperative image considerations for safety. Eur Spine J 22: 2481-2487.

9. Peltier E, Blondel B, Dufour H, Fuentes S (2013) Minimally invasive transmuscular approach for the treatment of lumbar herniated disc: far lateral lumbar disc herniation: a clinical study. Applications for cervical and thoracic disc herniation. J Neurosurg Sci 57: 123-127.

10. Salame K, Lidar Z (2010) Minimally invasive approach to far lateral lumbar disc herniation: technique and clinical results. Acta Neurochir (Wien) 152: 663-668.

11. Vogelsang J-P, Maier $H$ (2008) Clinical results and surgical technique for the treatment of extreme lateral lumbar disc herniations: the minimally invasive microscopically assisted percutaneous approach. Zentralblatt Für Neurochir 69: 35-39.

12. Voyadzis JM, Gala VC, Sandhu FA, Fessler RG (2010) Minimally invasive approach for far lateral disc herniations: results from 20 patients. Minim Invasive Neurosurg 53: 122-126.

13. Allen RT, Garfin SR (2010) The economics of minimally invasive spine surgery: the value perspective. Spine (Phila Pa 1976) 35: S375-382.

14. Arts MP, Brand R, van den Akker ME, Koes BW, Bartels RHMA, Tan WF, et al (2011) Tubular diskectomyvs conventional microdiskectomy for the treatment of lumbar disk herniation: 2-year results of a double-blind randomized controlled trial. Neurosurgery 69: 135-144

15. Brock M, Kunkel P, Papavero L (2008) Lumbar microdiscectomy: subperiostea versus transmuscular approach and influence on the early postoperative analgesic consumption. Eur Spine J OffPublEur Spine SocEur Spinal Deform SocEur Sect Cerv Spine Res Soc 17: 518-522.

16. Ee WW, Lau WL, Yeo W, Von Bing Y, Yue WM (2014) Does minimally invasive surgery have a lower risk of surgical site infections compared with open spinal surgery? ClinOrthopRelat Res 472: 1718-1724.

17. Kotilainen E (1998) Long-term outcome of patients suffering from clinical instability after microsurgical treatment of lumbar disc herniation. ActaNeurochir (Wien) 140: 120-125.

18. O'Toole JE, Eichholz KM, Fessler RG (2009) Surgical site infection rates after minimally invasive spinal surgery. J Neurosurg Spine 11: 471-476.

19. Ebeling U, Reulen HJ (1992) Are there typical localisations of lumbar disc herniations? A prospective study. Acta Neurochir (Wien) 117: 143-148.

20. Yeung AT, Tsou PM (2002)Posterolateral endoscopic excision for lumbar disc herniation: Surgical technique, outcome, and complications in 307 consecutive cases. Spine 27: 722-731.

21. Haji FA, Cenic A, Crevier L, Murty N, Reddy K (2011) Minimally invasive approach for the resection of spinal neoplasm. Spine (Phila Pa 1976) 36: E1018-1026.

22. Weil AG, Obaid S, Shehadeh M, Shedid D (2011) Minimally invasive removal of a giant extradural lumbar foraminalschwannoma. Surg Neurollnt 2: 186.

23. Viswanathan R, Swamy NK, Tobler WD, Greiner AL, Keller JT, et al. (2002 Extraforaminal lumbar disc herniations: microsurgical anatomy and surgical approach. J Neurosurg 96: 206-211.

24. Ahn Y (2012) Transforaminal percutaneous endoscopic lumbar discectomy technical tips to prevent complications. Expert Rev Med Devices 9: 361-366.

25. Ahn Y, Kim JU, Lee BH, Lee S-H, Park JD, Hong DH, et al. (2009) Postoperative retroperitoneal hematoma following transforaminal percutaneous endoscopic lumbar discectomy. J Neurosurg Spine10: 595-602.

26. Choi G, Modi HN, Prada N, Ahn TJ, Myung SH, et al. (2013) Clinical results of XMR-assisted percutaneous transforaminal endoscopic lumbar discectomy. J Orthop Surg Res 8: 14

27. Kim HS, Ju Cl, Kim SW, Kim JG (2009) Huge Psoas Muscle Hematoma due to Lumbar Segmental Vessel Injury Following Percutaneous Endoscopic Lumbar Discectomy. J Korean Neurosurg Soc 45: 192-195.

28. Matsumoto M, Hasegawa $T$, Ito M, Aizawa $T$, Konno S, Yamagata M, et al. (2010) Incidence of complications associated with spinal endoscopic surgery: nationwide survey in 2007 by the Committee on Spinal Endoscopic Surgical Skill Qualification of Japanese Orthopaedic Association. J Orthop Sci:92-96.

29. Savitz MH, Doughty H, Burns P (1998) Percutaneous lumbar discectomy with a working endoscope and laser assistance. Neurosurg Focus 4: e9. 
30. Park P, Upadhyaya C, Garton HJ, Foley KT (2008) The impact of minimally invasive spine surgery on perioperative complications in overweight or obese patients. Neurosurgery 62: 693-699.

31. Tomasino A, Parikh K, Steinberger J, Knopman J, Boockvar J, et al. (2009) Tubular microsurgery for lumbar discectomies and laminectomies in obese patients: operative results and outcome. Spine (Phila Pa 1976) 34: E664-672.

32. Epstein NE (2002) Foraminal and far lateral lumbar disc herniations: surgical alternatives and outcome measures. Spinal Cord 40: 491-500.

33. Gioia G, Mandelli D, Capaccioni B, Randelli F, Tessari L (1999) Surgical treatment of far lateral lumbar disc herniation. Identification of compressed root and discectomy by lateral approach. Spine (Phila Pa 1976) 24: 1952-1957.

34. Kawaguchi Y, Matsui H, Tsuji H (1996) Back muscle injury after posterior lumbar spine surgery. A histologic and enzymatic analysis. Spine (Phila $\mathrm{Pa}$ 1976) 21: $941-944$
35. Kawaguchi Y, Yabuki S, Styf J, Olmarker K, Rydevik B, et al. (1996) Back muscle injury after posterior lumbar spine surgery. Topographic evaluation of intramuscular pressure and blood flow in the porcine back muscle during surgery. Spine 21: 2683-2688.

36. Sihvonen T, Herno A, Paljärvi L, Airaksinen O, Partanen J, et al. (1993) Local denervation atrophy of paraspinal muscles in postoperative failed back syndrome. Spine (Phila Pa 1976) 18: 575-581.

37. Kotilainen E (1998) Long-term outcome of patients suffering from clinical instability after microsurgical treatment of lumbar disc herniation. Acta Neurochir (Wien) 140: 120-125.

38. Schaller B (2004) Failed back surgery syndrome: the role of symptomatic segmental single-level instability after lumbar microdiscectomy. Eur Spine $J$ 13: $193-198$.

39. Liu T, Zhou Y, Wang J, Chu TW, Li CQ, et al. (2012) Clinical efficacy of three different minimally invasive procedures for far lateral lumbar disc herniation. Chin Med J (Engl) 125: 1082-1088. 